\title{
New perspective on targeting the tumor suppressor p53 pathway in the tumor microenvironment to enhance the efficacy of immunotherapy
}

\author{
Gang Guo and Yan Cui
}

\begin{abstract}
About 50\% of human cancers harbor somatic mutations of the tumor suppressor p53 ( $p 53$ or Trp53) gene. Many of those mutations result in the inactivation of the p53 pathway and are often associated with the stabilization and accumulation of mutant p53 proteins. Therefore, increased p53 expression in tumors is frequently used as a surrogate marker for p53 mutation and inactivation. Moreover, this elevated p53 expression also makes it an ideal tumor associated antigen (TAA) for cancer vaccines. Recent advances in our understanding of p53 as a crucial transcription factor reveal that p53 is an important sensor of cellular stress under genotoxic, chemotoxic, pathological, and even normal physiological conditions. Experimental and clinical observations by our laboratory and others have demonstrated that p53 also participates in immune regulation as p53 dysfunction skews host immune responses towards pro-inflammation, which further promotes tumor progression. Furthermore, recent studies using a genetic approach revealed that p53-restoration or re-activation led to tumor regression and clearance, which were at least partially caused by the activation of innate antitumor immunity. Since many of the currently used cancer therapeutics, including radiotherapy and chemotherapy, disrupt tumor growth by inducing DNA damage via genotoxic or chemotoxic stress, which activates the p53 pathway in the tumor microenvironment, we postulate that some of those observed therapeutic benefits might also be partially mediated through their immune stimulatory effects. Here, we briefly review our current understanding of the potential cellular and molecular mechanisms by which p53 participates in immune regulation and, subsequently, extend our discussion to the immunostimulatory potential of existing and new approaches of targeting the p53-pathway to alter the immunological landscape of tumors for maximizing immunotherapy outcome.
\end{abstract}

Keywords: Cancer, Tumor suppressor p53, p53 inactivation, Tumor microenvironment, Immune suppression, Inflammation, Antitumor immunity, Immunotherapy

\section{Introduction}

The tumor suppressor p53 (also called transformation related protein 53, Trp53), was first described in 1979 as an oncogene, but was subsequently cloned and characterized as a tumor suppressor gene in its wild-type configuration in 1989 [1-4]. It is now known that $p 53$ encodes a crucial transcription factor controlling the life and death of a cell and is the most frequently mutated

\footnotetext{
* Correspondence: ycui@gru.edu
Department of Biochemistry and Molecular Biology, Cancer Immunology,
Inflammation \& Tolerance Program, Georgia Regents University Cancer

* Correspondence: ycui@gru.edu
Department of Biochemistry and Molecular Biology, Cancer Immunology,
Inflammation \& Tolerance Program, Georgia Regents University Cancer

* Correspondence: ycui@gru.edu
Department of Biochemistry and Molecular Biology, Cancer Immunology,
Inflammation \& Tolerance Program, Georgia Regents University Cancer Center, Augusta, GA 30912, USA
}

(c) 2015 Guo and Cui; licensee BioMed Central. This is an Open Access article distributed under the terms of the Creative Commons Attribution License (http://creativecommons.org/licenses/by/4.0), which permits unrestricted use, distribution, and reproduction in any medium, provided the original work is properly credited. The Creative Commons Public Domain Dedication waiver (http://creativecommons.org/publicdomain/zero/1.0/) applies to the data made available in this article unless otherwise stated.

gene in tumors [5-7]. Generally, about $50 \%$ of human tumors harbor $p 53$ mutations, mostly missense, although the frequency varies among different tumor types [5-7]. These mutations often cause conformational changes of the p53 protein, which consequently impairs its DNA binding capacity, resulting in loss of p53 function and reduced sensitivity to apoptosis or senescence, a permanent status of irreversible cell cycle arrest [7-9]. Furthermore, these conformational changes often stabilize the p53 protein resulting in an elevated p53 level in tumors, which is frequently used as a surrogate marker of p53 mutation [5-7,9]. Experimental and clinical evidence suggests that both mutant and BioMed Central 
wild-type p53 are immunogenic because anti-p53 antibodies and p53 antigen-specific $\mathrm{T}$ cells are detected in tumor patients [10-12]. Thus, both forms of p53 have been employed as tumor associated antigens (TAAs) in tumor vaccine clinical trials [13-15].

Even though $p 53$ is the best studied gene as the result of 30 years extensive research, our comprehension and appreciation of its complexity in regulating many crucial biological processes are far from complete [4,9,16-18]. Immunologically, besides using p53 as a TAA, whether p53 mutation and/or dysfunction imposes immunological consequences of promoting tumorigenesis has largely been unexplored. Numerous experimental and clinical results demonstrate that environmentally induced damage and genetic instability are associated with p53 dysfunction and inflammation [19-21]. Now that chronic inflammation is a well-accepted hallmark of cancer [22-24], it is plausible that $p 53$ dysfunction may also contribute immunologically to tumorigenesis and tumor progression by altering host immune responses. In fact, recent results from our laboratory and others have demonstrated that $p 53$ dysfunction skews tumor milieu towards pro-tumor inflammation [25-27], whereas p53 reactivation or restoration reverses the immunological landscape towards antitumor immunity [28-30]. Thus, it will be important for us to comprehend the mechanism of p53 activation-induced antitumor immunity and appreciate the unintended immunological components of conventional non-immunotherapy regimens that activate the p53 pathway. As the focus of this perspective review is on the involvement of p53 in immune modulation, we only present a brief and simplified view of the cellular and molecular pathways mediating p53 regulation and function. Subsequently, we extend our review and elaborative discussion to the immunological aspect of p53 function. We will conclude with new perspectives on future applications of maximizing antitumor efficacy by combining therapies targeting the p53 pathway with active immunotherapy.

\section{Review}

Trp53 - the master regulator of stress response and its canonical mechanism of tumor suppression

Trp53 is a master transcription factor that regulates the expression of a plethora of genes involved in crucial biological processes, many of which encode proteins that control the cell cycle or induce apoptosis $[7,8,31]$. Because of its critical impact on cell fate, cellular p53 activity must be precisely controlled. Usually, p53 is ubiquitously expressed in almost all cell types, but is barely detectable under normal physiological conditions in unstressed cells $[7,8]$. This low basal p53 level is controlled and regulated by its inhibitor molecules, MDM2 (mouse double minute 2 homolog) and MDM4 (also called MDMX). MDM2, an E3 ubiquitin ligase and the major regulator of p53 stability and activity, promotes the rapid degradation of $\mathrm{p} 53$ and prevents it from binding to the promoters of p53 target genes [32,33].

When a cell incurs DNA damage by genotoxic, chemotoxic stress, or receives aberrant signals from oncogene activation, p53 is activated causing an elevated level of p53 associated with its acetylation and phosphorylation (Figure 1) [7-9]. These post-translational modifications of p53 prevent its sequestration by MDM2, leading to its increased stability [32,33]. Activated p53 subsequently transactivates multiple molecular pathways, which induce cell cycle arrest and/or senescence via upregulating $\mathrm{p} 21$, the cyclin-dependent kinase inhibitor 1 , and apoptosis via promoting puma (p53 upregulated modulator of apoptosis), noxa, or bax (Bcl2-assocated X protein).

Recent emerging evidence reveals that p53 can also be activated by various physiological and pathological stressors, including hypoxia, ribosomal stress, endoplasmic reticulum (ER) stress, metabolic stress, nutrient deprivation, viral infection, and psychological stress $[9,16,17]$ (Figure 1). Thus, as a crucial sensor of cellular stress, p53 plays an important role in ensuring proper health and function of all cells by dictating their fate of apoptosis, senescence, or transient cell cycle arrest, depending on the level and nature of the stress as well as the severity and reversibility of the damage that cells incur (Figure 1) [7,8,34-37]. Though severe stress and unrepairable damage leads to apoptosis or senescence, modest stress and repairable damage causes transient cell cycle arrest. Cells will re-enter the cell cycle to produce progeny once the damage is repaired (Figure 1). This well regulated induction of apoptosis and senescence is considered the major mechanism by which p53 suppresses tumor development and ensures genome stability. Therefore, p53 is regarded as the caretaker, gatekeeper, and guardian of the genome $[7,8,31]$.

\section{Non-canonical and non-cell autonomous mechanisms of p53 mediated tumor suppression}

In the past decade, compelling evidence reveals that p53 participates in regulating a wide array of biological processes throughout the entire lifespan of the organism $[4,9,16,18,38-40]$. Thus, it is not surprising that $p 53$ dysfunction may result in dysregulation of many biological processes, such as stem cell homeostasis, metabolism, autophagy, angiogenesis, migration, and invasion [4,17,41-43], all of which are linked to the hallmarks of cancer $[23,44]$.

For instance, one of the hallmarks is the altered metabolic pathway in cancerous cells to glycolysis as the predominant source of ATP production, the so-called Warburg effect [45]. Recent studies demonstrated that p53 suppresses glycolysis in three ways: (1) reducing Glut3 


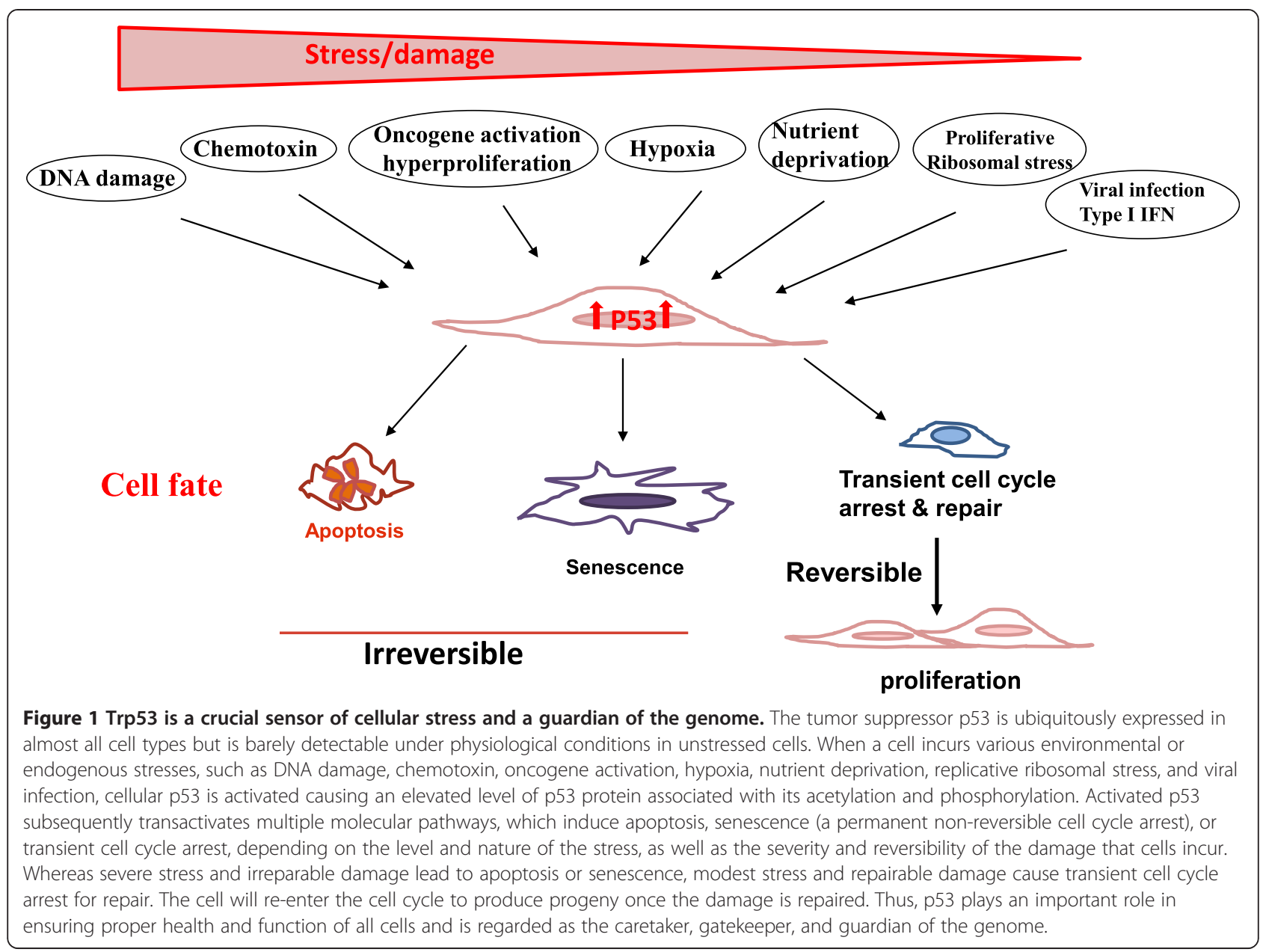

expression and, thus, suppressing glucose uptake; (2) enhancing the expression of mitochondrial respiratory enzyme SCO2 (synthesis of cytochrome c oxidase); and (3) promoting the expression of TIGAR (TP53-induced glycolysis and apoptosis regulator) [35,46-48]. Thus, p53 inactivation results in a switch to glycolysis by enhancing glucose uptake and reducing SCO2 and TIGAR. These observations shed light onto the molecular mechanism by which the Warburg effect in cancers can be caused by $p 53$ inactivation/dysfunction. Other studies also revealed that p53 activation promotes autophagy either directly via DRAM (damage regulated autophagy mediator) or indirectly via the AMP-activated protein kinase (AMPK) and the mTOR pathway [49-51]. In addition, p53 is also shown to suppress cell invasion by repressing the NF-kB mediated podia intrusion/formation and to inhibit epithelial-tomesenchymal transition (EMT) by suppressing the expression of SNAIL and ZEB (members of zinc-finger transcription factors) $[42,52-54]$. Therefore, the tumor suppressive function of p53 is partially mediated by altering cellular metabolism, motility, and invasion [55,56], which are considered non-canonical mechanisms.
In addition to the aforementioned direct effects on tumor cells, p53 also suppresses tumorigenesis via changing the function and property of cells adjunct to tumors, such as cancer associated fibroblasts (CAFs). Clinical and experimental evidence confirms the existence of somatic p53 mutations in CAFs and highly inflamed pathological tissues [57-60]. Moreover, p53 mutations in CAFs of breast and prostate cancer patients, whose cancer cells maintain wild-type p53 function, were associated with an increased rate of metastasis and poor prognosis $[5,58,59,61]$. These results suggest that $p 53$ dysfunction in CAFs serves as a selective pressure for the transformation of adjacent epithelial cells [62]. This tumor suppressive effect of p53 via altering the milieu of transformed cells is regarded as the non-cell-autonomous mechanism $[57,62]$. Accumulating evidence suggests that tumor progression and metastases are markedly affected by the molecular and cellular constituents surrounding the tumors, the so-called tumor microenvironment (TME) [63-65]. It is now greatly appreciated that both the cellular and molecular components of the TME 
are highly complex. The cellular compartment consists of immune cells of T-, B-, NK-, and myeloid cells and non-hematopoietic stromal cells, including CAFs, lymphatic, and blood endothelial cells (Figure 2). The molecular components that greatly impact tumor progression include integrins and other extracellular matrix proteins, cytokines, and chemokines. Mechanistic studies revealed that the pro-tumor effect of $p 53$-dysfunctional CAFs is mediated through enhanced production of cytokines and chemokines, including SDF-1 and IL-6, which further affected immune cell composition and function within the TME $[25,57,66,67]$. Together, these observations showed that p53 dysfunction in tumors or other populations within the TME also promotes tumor progression and metastasis via mechanisms including, but not limited to, the suppression of apoptosis and/or senescence.

\section{Immunosuppressive effects of $p 53$ dysfunction on the host immunological landscape}

Compelling evidence demonstrates that chronic inflammation plays a vital role in tumor initiation, progression, and metastasis $[20,23,24,68,69]$. Nevertheless, it has not been explored systemically whether p53 participates in immune regulation or whether $p 53$ inactivation causes chronic inflammation, further promoting tumorigenesis and tumor progression.

Interestingly, it was observed as early as the 1980s that p53 expression was elevated in mitogen-stimulated or T cell receptor (TCR)-ligation activated T cells [70,71]. Subsequent experiments and clinical observations further confirmed the activation or alteration of the p53 pathway during immune responses and in inflamed pathological tissues; however, the immunological significance of p53 activation remains unknown [72-75]. Based on the observations that $p 53$ inactivation exacerbated autoimmune disease in mice [76,77], we and others proposed that p53 suppresses autoimmunity by inhibiting inflammation $[20,21,26,76]$. Specifically, Zheng et al. showed that $p 53$ inactivation enhanced the production of inflammatory cytokines IL- $1,-6$, and -12 by macrophages [76] while we demonstrated that the genetic deletion of $p 53$ enhanced IL-6-induced Th17 differentiation and promoted the spontaneous development of autoimmunity in $p 53^{\text {null }} C D 45.1$ mice [26]. Because Th17/IL-17 activity has been linked to inflammation, autoimmunity, and tumorigenesis [78-80], these observations further support the role of $p 53$ inactivation in inflammation-induced tumorigenesis.

Importantly, this $p 53$ inactivation mediated elevation of inflammatory molecules is not restricted to immune cells because $p 53$ mutations/inactivation in CAFs also augment their production of pro-inflammatory molecules $[25,58,59,61]$, which is associated with increased metastasis and poor prognosis $[66,81,82]$. It is noteworthy that in cells maintaining wild-type $p 53$, functional inactivation of the p53 pathway can also be instigated by other means, such as overexpression of the p53 inhibitor MDM2 or the viral proteins HPV E6 and HLTV-1 Tax, all of which have been linked to tumorigenesis [83-88].

Mechanistically, it has been suggested that p53 activity has an inverse correlation with that of NF- $\mathrm{BB}$, a
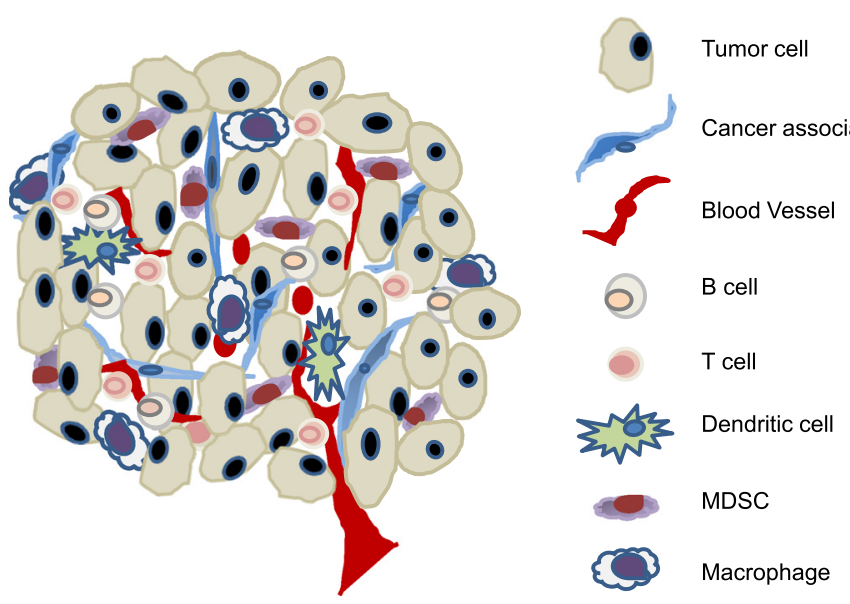

Figure 2 Cellular constituents of the tumor microenvironment that shape the immunological landscape of tumor. The tumor microenvironment consists of complex molecular and cellular constituents. Tumor regression or progression is dictated by its immunological landscape, i.e. activated antitumor immunity or tumor-induced immune tolerance/immunosuppression, which is reflected by the activation status of T and B lymphocytes, NK cells, macrophages, dendritic cells, and other myeloid derived cells. Importantly, the immunological landscape is also greatly impacted by cells of the non-hematopoietic compartment, including cancer associated fibroblasts (CAFs) and endothelial cells of the lymphatic and blood vasculature. Moreover, $p 53$ inactivation has been reported to occur in various cells within the tumor microenvironment, such as CAFs, which further promotes immunosuppression and augmented tumor progression. Therefore, targeted activation of the p53 pathway to enhance antitumor immunity should not limited to tumor cells, but extend to cellular compartments of the CAFs and potentially immune cells as well. 
major transcription regulator of inflammatory response $[21,89,90]$. It is believed that the reciprocal activities of the p53 and NF- $\mathrm{kB}$ are the result of their competition for the limited transcription coactivator p300 and the CREB-binding protein $[21,89,90]$. Recent studies also demonstrated that p53 inhibits NF-kB-dependent genes by directly suppressing the promoter activity of NF- $\mathrm{kB}$ subunit p65 or indirectly repressing the activity of IKK $\alpha$, a subunit of IкB $\alpha$ kinase complex [48,90,91]. Thus, p53 suppresses the expression of IL-6, Cox-2, and iNOS, and thereby inflammation, by inhibiting NF-kB activity $[20,21,89]$. Likewise, $p 53$ inactivation causes the hyperactivity of NF- $\mathrm{kB}$ in $p 53^{\text {null }} \mathrm{T}$ cells, macrophages, and intestinal epithelium, leading to chronic inflammation and tumorigenesis as shown by us and others $[26,76,91,92]$.

It is noteworthy that the reciprocal activity of the p53 and NF- $\mathrm{kB}$ is not exclusive because the coactivation of p53 and NF- $\mathrm{kB}$ was also observed under certain circumstances [21,93]. For instance, Lowe and colleagues demonstrated that p53 and NF- $\mathrm{kB}$ соregulate IL-6 production in human macrophages [93]. Additionally, it has been well established that senescent cells secrete numerous inflammatory cytokines, chemokines, growth factors, and other soluble proteins to the extracellular space, which subsequently activate NF- $\mathrm{kB}[94,95]$. Interestingly, the p53-dependent release of the chromatin protein high-mobility group box 1 (HMGB1) by senescent cells is a major mediator of their secretion of other inflammatory molecules via activation of TLR-4 and NF- $k B$ [95]. Thus, the co-activation of p53 and NF-kB also occurs in senescent cells. Nevertheless, it is not yet fully understood how pro-inflammatory molecules produced by senescent cells promote antitumor immunity in certain conditions but enhance pro-tumorigenic inflammation under other circumstances $[30,62,94]$.

Altogether, these results suggest that p53 may serve as a general suppressor of innate immunity and inflammation. Trp53 dysfunction in either hematopoietic or nonhematopoietic populations alters the immunological landscape of the host/TME to pro-inflammation, thereby immunologically promoting tumorigenesis and tumor progression.

\section{New insights into the immunological components of therapeutic interventions that activate the p53 pathway} It is now appreciated that activation of anti-tumor immunity is indispensable for the therapeutic benefits of conventional therapies [96-99]. Recent mechanistic studies illustrated that only those therapies eliciting tumor immunogenic cell death (ICD), such as radiotherapy and some chemotherapy regimens, induce a robust anti-tumor immunity [96-100]. On the other hand, therapies causing non-immunogenic death of tumors fail to stimulate a strong antitumor immunity as they are unable to overcome tumor-induced immune tolerance. So far, the identified molecular processes crucial for ICD include the following: (1) the exposure of ER proteins, such as calreticulin (CRT), at the cell surface; (2) the secretion of ATP to extracellular space, which is frequently associated with autophagy; and (3) the release of HMGB1 to extracellular space $[96,99]$.

Although it is well established that radiotherapy and most of the chemotherapy regimens induce DNA damage via genotoxic and chemotoxic stress, which activate the p53 pathway in cells maintaining functional p53 (Figure 1) $[7,8]$, it is yet to be verified clinically whether p53 activation induced in those therapies contribute to the induction of antitumor immunity. Experimentally, animal studies with p53 re-activation or restoration in either tumors or stroma confirmed that tumor regression and clearance are dependent on senescenceinduced antitumor immunity [30,62]. As discussed earlier, senescent cells secret HMGB1, inflammatory cytokines, and chemokines to extracellular space [95]. It is conceivable that p53 activation-induced cellular senescence may subsequently trigger autophagy or ICD of cells in the TME, thereby activating antitumor immunity. Alternatively, it is also possible that direct killing of tumors by activated NK cells as the result of p53activation alters the immunological milieu of tumors to immune stimulatory despite not meeting all the aforementioned characteristics of ICD. In fact, it has been demonstrated that DNA damage and/or p53 activation, either dependent or independent of each other, upregulate the expression of NKG2D ligand such as ULBP2, greatly enhance NK mediated tumor elimination, and alter the antigen presentation capacity of tumors and stromal cells toward immune-stimulation [101-106]. Subsequently, this leads to the production of type I interferon (IFN), activation of M1 macrophages, enhancement of the antigen presentation capacity of tumors, APCs, and stromal cells, and recruitment of immune cells to the TME, all of which synergistically promote antitumor immunity [97-100,107-111]. Furthermore, Taura et al. and Shatz et al. demonstrated that p53 activation upregulates the expression and function of toll-like receptors (TLR)-3 or -8 in human cancers, lymphocytes, alveolar type I cells, and epithelial cell lines $[27,112,113]$. Likewise, p53 also interacts with IFN regulatory factors (IRF), specifically IRF-5 and IRF-9, and IFN-stimulated gene factor 3 (ISGF3) at various phases of anti-viral immunity [114-116], as well as in cancer cells treated with IFN and a DNA damage agent $[117,118]$. As both TLR ligands and IFN-alpha are potent immune adjuvants that have been employed for cancer immunotherapy, it is also plausible that some of the immunostimulatory effects of conventional therapies that induce p53 activation are mediated through 
enhancing the TLR and IFN pathways. Certainly, more in-depth studies are necessary before any definitive conclusions are drawn.

Together, these results suggest that p53-activation either in tumors or stroma by some conventional therapies elicits both innate and adaptive anti-tumor immunity via various molecular mechanisms. It has yet to be clarified whether some of the observed immune-stimulatory effects might be mediated through a p53-independant pathway, especially in tumors incurring $p 53$ mutations. Nevertheless, it is also important and clinically relevant to examine whether immune responses initiated by p53activation in CAFs that maintain functional p53 may overcome the unresponsiveness or, even worse, immune tolerance induced by tumors that incur $p 53$ mutations. Further studies are necessary to clarify the contribution and quality of p53-activation in promoting antitumor immunity for improving the outcome of immunotherapy $[96,98,100,109,110,119]$.

\section{Therapeutic strategies of targeted activation and/or restoration of the p53 pathway as adjuvant for enhancing antitumor immunity - current status and new perspective} As discussed above, the immunostimulatory properties of radiotherapy and chemotherapy have received increasing appreciation [98-100,107,109-111]. Importantly, some of the cellular and molecular processes that dictate the outcome of immune stimulation vs. tolerance are better comprehended, although still evolving $[96,99]$. This better understanding provides a mechanistic explanation of why some of the apparently similar therapies are immunostimulatory at times, but immunosuppressive under other circumstances $[96-100,120]$. It is also noteworthy that high dose systemic radiation or chemotherapy regimens may impose the side effects of inducing mutagenesis and drug resistance in tumors, besides the lymphoid-hematopoietic toxicity to the host $[98,102]$. Therefore, it is important for us to better define the following: (1) whether the level or duration of p53 activation dictates the immunological outcome of antitumor immunity so that unnecessary damages can be controlled or avoided altogether, and (2) whether the tumor/host $p 53$ dysfunction, either pre-existing or therapy-induced, may skew antitumor immunity to protumor inflammation. Clarification of these issues will facilitate the development of more effective strategies combining p53-activation induced $\mathrm{ICD} /$ senescence with active immunotherapy to maximize therapeutic benefits.

Because p53 mutation/inactivation is one of major causes of cancer, targeting the p53 pathway via viral vector mediated $p 53$ delivery or small molecule p53-activators has been an important approach for cancer treatment over the past decades and is still rapidly evolving [121-123]. Different from other conventional therapies, these approaches have greatly reduced risk of lymphoid-hematopoietic toxicity and mutagenesis because they do not induce DNA damage. On the other hand, the immunological properties of most of the currently tested p53-activation regimens have not been explored because they were developed preceding our comprehension and appreciation of p53 activation to antitumor immunity. Here, we will focus our review on the approaches directly targeting the p53 pathway, other than the radiotherapy and chemotherapy that we already discussed above, with insights on their potential immunological effects and capacity for promoting antitumor immunity.

\section{Viral vector-mediated p53 re-introduction or restoration gene therapy}

Adenoviral delivery of exogenous $p 53$ (Ad-p53) to tumors represents one of the first series of p53 targeted clinical trials for multiple tumor types worldwide [124-126]. Despite demonstrated p53-induced apoptosis, the clinical outcome of Ad-p53 therapy has been less than satisfactory due to limited intra-tumor delivery. To improve the delivery efficacy and utilize the $p 53$-inactivated nature of many tumors, more advanced vector systems have been developed. For instance, the oncolytic adenovirus ONYX-015 is capable of replicating only in $p 53$-defective tumors and inducing their apoptosis [127-129]. So far, these viruses showed limited therapeutic efficacy [127-131]. Due to lack of immunological data, we can only speculate that the less than satisfactory efficacy is due to either the limited activation of p53 not sufficient to induce antitumor immunity [124-126] or the oncolytic virus induced tumor death is non-ICD leading to immune tolerance [127-129]. Interestingly, a clinical trial combining Ad-p53 with chemotherapy by Nemunaitis and colleagues showed certain levels of clinical response [130], implying that an elevated p53 activity in the TME, potentially stromal cells that maintain p53 function, subsequently enhanced antitumor efficacy. However, a more definitive conclusion cannot be drawn in the absence of clinical assessment of immune responses and p53 activity associated with this trial.

\section{Small molecule based therapy targeting the p53-MDM2 axis} The E3 ubiquitin ligase MDM2 is a crucial p53 inhibitor. Many tumors, especially hematopoietic malignancies, exhibit loss of p53 function as the result of MDM2 amplification while maintaining wild-type $p 53[32,132]$. To target this MDM2-amplification induced functional p53 inactivation, small molecule MDM2 antagonists were developed to re-activate the p53 pathway $[132,133]$. For instance, Nutlin3 , one of the MDM2 antagonists that occupies the p53 interacting pocket of MDM2, enacts anti-tumorigenic and anti-metastatic effects by preventing p53 degradation, thereby selectively inducing apoptosis and/or senescence of tumor cells $[133,134]$. Similarly, RITA (reactivation of p53 and induction of tumor cell apoptosis), another small molecule that inhibits the binding of HDM2 (human double 
minus-2, the human analogue of MDM2), also induces tumor specific p53 activation [132,135]. Overall, the therapeutic effects of these pharmacological p53-activators require the existence of wild-type $p 53$, as they are ineffective in tumors with mutant $p 53$. Although most of the published studies focus on MDM2 inhibition-induced tumor cell apoptosis, a couple of recent observations demonstrated that Nultin-3 also regulates host immune response by modulating the immunological function of dendritic cells or other antigen presenting cells [136,137], making it a potential candidate of immunotherapy adjuvant. To fully appreciate the effects and quality of p53 activation in promoting antitumor immunity, additional studies to address dose-dependent effects of Nultin-3 or RITA in mediating p53 activation and antitumor immunity are necessary. Furthermore, our better understanding of their cellular and molecular mechanisms of immune activation will greatly expand their clinical application for immunotherapy.

\section{Restoration of mutant p53 to wild-type configuration and function}

Since many p53 mutants are associated with a conformational change that hinders its DNA binding and transactivation capacity, it is rationalized that small molecules that revert the mutant p53 to its wild-type configuration will restore p53 function. Indeed, based on crystallographic structural and computational analyses, PRIMA-1 (p53 reactivation and induction of massive apoptosis-1) and MIRA-3 (mutant p53 reactivation and induction of rapid apoptosis in vivo) were developed to convert mutant p53 and restore p53 function leading to effective activation of downstream apoptosis-inducing targets, such as caspase-2, puma, and Bax $[138,139]$. Again, previous studies on antitumor effects of p53 reactivation via reverting p53 mutations mainly focused on the nonimmunological aspects. With our better understanding of the immunological component of anti-tumor effects of p53 activation, these small molecules will be valuable tools for evaluating the immunological impact of p53 reactivation in various compartments of the TME, such as tumor or CAFs, both have been shown to incur p53 mutations independent of each other. Thus, these molecules will allow us to examine whether p53 reactivation either in tumors or stroma is sufficient to reverse $p 53$ dysfunction-induced immunosuppression and the level of p53 reactivation required to achieve sufficient antitumor immunity to overcome tumor-induced immune tolerance.

\section{Combining p53-activation therapy with active immunotherapy to improve therapeutic efficacy}

Accumulating evidence suggests that monotherapy of surgery, radiation, chemotherapy, or even single-pronged immunotherapy is insufficient to achieve satisfactory therapeutic outcome, whereas combinational approaches that not only debunk tumors, but also elicit strong antitumor immunity during tumor debunking improve therapeutic efficacy $[96,98,111,140]$.

Given the documented immune stimulatory property of radiotherapy, some chemotherapies, and the potential immune adjuvant function of the above described pharmalogical p53-activators, we believe that combining these therapies with active immunotherapy will further enhance the desired antitumor immunity. Because the small molecule p53-activators not only re-activate, but also reverse p53 dysfunction associated with p53 mutations, they will provide the additional advantage of reversing p53 dysfunction-induced immune tolerance or immunosuppression of the TME to augment antitumor efficacy of active immunotherapy for tumors with both wild-type and mutant $p 53$.

Certainly, radiotherapy and some chemotherapy regimens can stimulate similar levels, if not higher, of p53activation in tumors maintaining wild-type $p 53$ as compared with pharmacological p53-activators. An additional immunostimulatory benefit associated with radiotherapy and chemotherapy, but not pharmacological p53-activators, is the transient lymphopenia in the host, which is important for adoptive $\mathrm{T}$ cell transferred based immunotherapy as it enhances T cell activation and expansion [98]. Moreover, it also has been shown that low doses of cyclophosphamide selectively suppresses the immunoinhibitory regulatory $\mathrm{T}$ cells, thereby enhancing antitumor immunity [98], which has not been seen in p53-pharmacological activators.

Therefore, pharmacological p53-activators and radio- $/$ chemotherapy mediated p53-activation each has their own unique advantages and associated drawbacks. Their immunostimulatory potency in combination with active immunotherapy and translational potential will not been known until tested side-by-side. It is very likely that the selection of one approach over another will be tumor and case-specific, depending on the integrity of the p53 pathway and the TME. More in depth comparative studies are warranted before their broader clinical applications as an adjuvant for tumor immunotherapies.

\section{Conclusions}

Despite more than 30 years of extensive studies on p53 with more than 60,000 publications, our understanding of the complexity of p53 pathway and its regulation in many biological processes is far from complete. It is indisputable that p53 suppresses tumorigenesis via the canonical pathway of inducing apoptosis and/or senescence and the noncanonical pathways, some of which are still emerging. Conversely, p53 dysfunction-induced tumorigenesis is mediated by loss of cell cycle arrest and apoptosis, as well as by compromising host immune surveillance and altering tumor milieu to pro-tumor inflammation. This immune 
regulatory function of p53 is particularly exciting for tumor immunotherapy as p53-reactivation and restoration is no longer the sole molecular biology approach for cancer treatment. Instead, targeting the p53 activity and pathway, either via conventional chemotherapy and radiotherapy or the novel pharmacological activators, will prove to be more clinically important as they provide dual therapeutic effects of direct p53-activation/restoration mediated tumor killing and enhanced immune activation to promote antitumor immunity. More importantly, they can be used in combination with other active immunotherapies to maximize ultimate antitumor efficacy for tumors maintaining wild-type p53 and incurring p53 mutations. Therefore, a better understanding of how p53 activity and of specific mechanisms/pathways that may ultimately revert tumor-induced immune tolerance to heightened immune activation is clinically significant for improving therapeutic outcome.

\begin{abstract}
Abbreviations
Trp53: p53, Transformation-related protein 53, tumor suppressor p53; TAA: Tumor associated antigen; TME: Tumor microenvironment; MDM2: Mouse double minute 2 homolog; SCO2: Synthesis of cytochrome c oxidase; TIGAR: TP53-induced glycolysis and apoptosis regulator; DRAM: Damage regulated autophagy mediator; AMPK: AMP-activated protein kinase; EMT: Epithelial to mesenchymal transition; CAF: Cancer associated fibroblasts; AICD: Activation-induced cell death; MDSC: Myeloid derived suppressor cell; STAT: Signal transducers and activators of transcription; HMGB1: High-mobility group box 1; ICD: Immunogenic cell death; IRF: Interferon regulatory factor; ISGF: Interferon stimulated gene factor; RITA: Reactivation of p53 and induction of tumor cell apoptosis; PRIMA-1: P53 reactivation and induction of massive apoptosis-1; MIRA-3: Mutant p53 reactivation and induction of rapid apoptosis.
\end{abstract}

\section{Competing interests}

The authors declare that they have no competing interests.

\section{Authors' contributions}

GG reviewed the literature, drafted the manuscript, compiled the references, and participated in discussion and revision. YC conceived the study and review, participated in discussion and revision of the manuscript. Both authors read and approved the final manuscript.

\section{Acknowledgements}

This study is supported by 01CA169133 from NCI/NIH and funds from GRU Cancer Center to YC.

Received: 26 August 2014 Accepted: 26 February 2015

Published online: 24 March 2015

\section{References}

1. Lane DP, Crawford LV. T antigen is bound to a host protein in SV40-transformed cells. Nature. 1979;278(5701):261-3.

2. Finlay CA, Hinds PW, Levine AJ. The p53 proto-oncogene can act as a suppressor of transformation. Cell. 1989;57(7):1083-93.

3. Eliyahu D, Michalovitz D, Eliyahu S, Pinhasi-Kimhi O, Oren M. Wild-type p53 can inhibit oncogene-mediated focus formation. Proc Natl Acad Sci U S A. 1989;86(22):8763-7.

4. Lane D, Levine A. p53 Research: the past thirty years and the next thirty years. Cold Spring Harb Perspect Biol. 2010;2(12):a000893.

5. Soussi T. p53 alterations in human cancer: more questions than answers. Oncogene. 2007;26(15):2145-56.

6. Soussi T, Hamroun D, Hjortsberg L, Rubio-Nevado JM, Fournier JL, Beroud C. MUT-TP53 2.0: a novel versatile matrix for statistical analysis of TP53 mutations in human cancer. Hum Mutat. 2010;31(9):1020-5.

7. Vousden KH, Lane DP. p53 in health and disease. Nat Rev. 2007;8(4):275-83.
8. Levine AJ. p53, the cellular gatekeeper for growth and division. Cell. 1997;88 (3):323-31.

9. Levine AJ, Oren M. The first 30 years of p53: growing ever more complex. Nat Rev Cancer. 2009;9(10):749-58.

10. Shimada H, Takeda A, Arima M, Okazumi S, Matsubara H, Nabeya Y, et al. Serum p53 antibody is a useful tumor marker in superficial esophageal squamous cell carcinoma. Cancer. 2000;89(8):1677-83.

11. Tang R, Yeh CY, Wang JY, Changchien CR, Chen JS, Hsieh LL. Serum p53 antibody as tumor marker for follow-up of colorectal cancer after curative resection. Ann Surg Oncol. 2009;16(9):2516-23.

12. Tilkin AF, Lubin R, Soussi T, Lazar V, Janin N, Mathieu MC, et al. Primary proliferative $T$ cell response to wild-type p53 protein in patients with breast cancer. Eur J Immunol. 1995;25(6):1765-9.

13. DeLeo AB, Whiteside TL. Development of multi-epitope vaccines targeting wild-type sequence p53 peptides. Expert Rev Vaccines. 2008;7(7):1031-40.

14. Vermeij R, Leffers $N$, van der Burg SH, Melief CJ, Daemen T, Nijman HW. Immunological and clinical effects of vaccines targeting p53-overexpressing malignancies. J Biomed Biotechnol. 2011;2011:702146.

15. Chiappori AA, Soliman H, Janssen WE, Antonia SJ, Gabrilovich DI. INGN-225: a dendritic cell-based p53 vaccine (Ad.p53-DC) in small cell lung cancer: observed association between immune response and enhanced chemotherapy effect. Expert Opin Biol Ther. 2010;10(6):983-91.

16. Vousden $\mathrm{KH}$, Prives $\mathrm{C}$. Blinded by the Light: The Growing Complexity of p53. Cell. 2009;137(3):413-31.

17. Levine AJ. Introduction: The Changing Directions of p53 Research. Genes Cancer. 2011;2(4):382-4.

18. Aylon Y, Oren M. New plays in the p53 theater. Curr Opin Genet Dev. 2011;21(1):86-92.

19. Hussain SP, Amstad P, Raja K, Ambs S, Nagashima M, Bennett WP, et al. Increased p53 mutation load in noncancerous colon tissue from ulcerative colitis: a cancer-prone chronic inflammatory disease. Cancer Res. 2000;60 (13):3333-7.

20. Schetter AJ, Heegaard NH, Harris CC. Inflammation and cancer: interweaving microRNA, free radical, cytokine and p53 pathways. Carcinogenesis. 2010;31 (1):37-49.

21. Gudkov AV, Gurova KV, Komarova EA. Inflammation and p53: A Tale of Two Stresses. Genes Cancer. 2011;2(4):503-16.

22. Colotta F, Allavena P, Sica A, Garlanda C, Mantovani A. Cancer-related inflammation, the seventh hallmark of cancer: links to genetic instability. Carcinogenesis. 2009;30(7):1073-81.

23. Hanahan D, Weinberg RA. Hallmarks of cancer: the next generation. Cell. 2011;144(5):646-74.

24. Grivennikov SI, Greten FR, Karin M. Immunity, inflammation, and cancer. Cell. 2010;140(6):883-99.

25. Guo G, Marrero L, Rodriguez P, Del Valle L, Ochoa A, Cui Y. Trp53 inactivation in the tumor microenvironment promotes tumor progression by expanding the immunosuppressive lymphoid-like stromal network. Cancer Res. 2013;73(6):1668-75

26. Zhang S, Zheng M, Kibe R, Huang Y, Marrero L, Warren S, et al. Trp53 negatively regulates autoimmunity via the STAT3-Th17 axis. Faseb J. 2011;25 (7):2387-98.

27. Menendez D, Shatz M, Resnick MA. Interactions between the tumor suppressor p53 and immune responses. Curr Opin Oncol. 2013;25 (1):85-92

28. Martins CP, Brown-Swigart L, Evan Gl. Modeling the therapeutic efficacy of p53 restoration in tumors. Cell. 2006;127(7):1323-34.

29. Ventura A, Kirsch DG, McLaughlin ME, Tuveson DA, Grimm J, Lintault L, et al. Restoration of p53 function leads to tumour regression in vivo. Nature. 2007;445(7128):661-5.

30. Xue W, Zender L, Miething C, Dickins RA, Hernando E, Krizhanovsky V, et al. Senescence and tumour clearance is triggered by p53 restoration in murine liver carcinomas. Nature. 2007:445(7128):656-60.

31. Vogelstein B, Lane D, Levine AJ. Surfing the p53 network. Nature. 2000;408 (6810):307-10.

32. Wade M, Wang $\mathrm{V}$, Wahl GM. The p53 orchestra: Mdm2 and Mdmx set the tone. Trends Cell Biol. 2010;20(5):299-309.

33. Kruse JP, Gu W. Modes of p53 regulation. Cell. 2009;137(4):609-22.

34. Levine AJ, Hu W, Feng Z. The P53 pathway: what questions remain to be explored? Cell Death Differ. 2006;13(6):1027-36.

35. Green DR, Chipuk JE. p53 and metabolism: Inside the TIGAR. Cell. 2006;126 (1):30-2. 
36. Stiewe T. The p53 family in differentiation and tumorigenesis. Nat Rev Cancer. 2007;7(3):165-8.

37. Junttila MR, Evan Gl. p53-a Jack of all trades but master of none. Nat Rev Cancer. 2009:9(11):821-9.

38. Menendez D, Inga A, Resnick MA. The expanding universe of p53 targets. Nat Rev Cancer. 2009:9(10):724-37.

39. Feng Z, Hu W, Rajagopal G, Levine AJ. The tumor suppressor p53: cancer and aging. Cell cycle (Georgetown, Tex. 2008;7(7):842-7.

40. Vigneron A, Vousden KH. p53, ROS and senescence in the control of aging Aging. 2010;2(8):471-4

41. Yi L, Lu C, Hu W, Sun Y, Levine AJ: Multiple Roles of p53-Related Pathways in Somatic Cell Reprogramming and Stem Cell Differentiation. Cancer Res 2012;72:5635-45.

42. Muller PA, Caswell PT, Doyle B, Iwanicki MP, Tan EH, Karim S, et al. Mutant p53 drives invasion by promoting integrin recycling. Cell. 2009;139(7):1327-41.

43. Rivlin N, Koifman G, Rotter V: p53 orchestrates between normal differentiation and cancer. Seminars in cancer biology 2014; epub available online 7 January 2014. doi:10.1016/j.semcancer.2013.12.006.

44. Hussain SP, Hollstein MH, Harris CC. p53 tumor suppressor gene: at the crossroads of molecular carcinogenesis, molecular epidemiology, and human risk assessment. Ann N Y Acad Sci. 2000;919:79-85.

45. Warburg O. On respiratory impairment in cancer cells. Science. 1956;124 (3215):269-70.

46. Bensaad K, Tsuruta A, Selak MA, Vidal MN, Nakano K, Bartrons R, et al. TIGAR, a p53-inducible regulator of glycolysis and apoptosis. Cell. 2006;126(1):107-20.

47. Matoba S, Kang JG, Patino WD, Wragg A, Boehm M, Gavrilova O, et al. p53 regulates mitochondrial respiration. Science. 2006;312(5780):1650-3.

48. Kawauchi K, Araki K, Tobiume K, Tanaka N. p53 regulates glucose metabolism through an IKK-NF-kappaB pathway and inhibits cell transformation. Nat Cell Biol. 2008;10(5):611-8.

49. Jones RG, Plas DR, Kubek S, Buzzai M, Mu J, Xu Y, et al. AMP-activated protein kinase induces a p53-dependent metabolic checkpoint. Mol Cell. 2005;18 (3):283-93

50. Thoreen CC, Sabatini DM. AMPK and p53 help cells through lean times. Cell Metab. 2005;1(5):287-8

51. Crighton D, Wilkinson S, O'Prey J, Syed N, Smith P, Harrison PR, et al. DRAM, a p53-induced modulator of autophagy, is critical for apoptosis. Cell. 2006;126(1):121-34.

52. Muller PA, Vousden KH, Norman JC. p53 and its mutants in tumor cell migration and invasion. J Cell Biol. 2011;192(2):209-18.

53. Guo AK, Hou YY, Hirata H, Yamauchi S, Yip AK, Chiam KH, et al. Loss of p53 enhances NF-kappaB-dependent lamellipodia formation. J Cell Physiol. 2014;229(6):696-704.

54. Yamauchi S, Hou YY, Guo AK, Hirata H, Nakajima W, Yip AK, et al. p53-mediated activation of the mitochondrial protease $\mathrm{HtrA2} / \mathrm{Omi}$ prevents cell invasion. J Cell Biol. 2014;204(7):1191-207.

55. Bieging KT, Mello SS, Attardi LD. Unravelling mechanisms of p53-mediated tumour suppression. Nat Rev Cancer. 2014;14(5):359-70.

56. Hager KM, Gu W. Understanding the non-canonical pathways involved in p53-mediated tumor suppression. Carcinogenesis. 2014;35(4):740-6.

57. Kiaris H, Chatzistamou I, Trimis G, Frangou-Plemmenou M, Pafiti-Kondi A, Kalofoutis A. Evidence for nonautonomous effect of p53 tumor suppressor in carcinogenesis. Cancer Res. 2005;65(5):1627-30.

58. Hill R, Song Y, Cardiff RD, Van Dyke T. Selective evolution of stromal mesenchyme with p53 loss in response to epithelial tumorigenesis. Cell. 2005;123(6):1001-11.

59. Patocs A, Zhang L, Xu Y, Weber F, Caldes T, Mutter GL, et al. Breast-cancer stromal cells with TP53 mutations and nodal metastases. N Engl J Med. 2007;357(25):2543-51.

60. Yamanishi Y, Boyle DL, Green DR, Keystone EC, Connor A, Zollman S, et al. p53 tumor suppressor gene mutations in fibroblast-like synoviocytes from erosion synovium and non-erosion synovium in rheumatoid arthritis. Arthritis Res Ther. 2005; $7(1): R 12-8$.

61. Fukino K, Shen L, Patocs A, Mutter GL, Eng C. Genomic instability within tumor stroma and clinicopathological characteristics of sporadic primary invasive breast carcinoma. JAMA. 2007:297(19):2103-11.

62. Lujambio A, Akkari L, Simon J, Grace D, Tschaharganeh DF, Bolden JE, et al. Non-cell-autonomous tumor suppression by p53. Cell. 2013;153 (2):449-60.
63. Gajewski TF, Meng Y, Blank C, Brown I, Kacha A, Kline J, et al. Immune resistance orchestrated by the tumor microenvironment. Immunol Rev. 2006;213:131-45

64. Kerkar SP, Restifo NP. Cellular constituents of immune escape within the tumor microenvironment. Cancer Res. 2012;72(13):3125-30.

65. Swartz MA, lida N, Roberts EW, Sangaletti S, Wong MH, Yull FE, et al. Tumo microenvironment complexity: emerging roles in cancer therapy. Cancer Res. 2012;72(10):2473-80.

66. Orimo A, Gupta PB, Sgroi DC, Arenzana-Seisdedos F, Delaunay T, Naeem R, et al. Stromal fibroblasts present in invasive human breast carcinomas promote tumor growth and angiogenesis through elevated SDF-1/CXCL12 secretion. Cell. 2005;121(3):335-48.

67. Orimo A, Weinberg RA. Heterogeneity of stromal fibroblasts in tumors. Cancer Biol Ther. 2007:6(4):618-9.

68. Coussens LM, Werb Z. Inflammation and cancer. Nature. 2002:420 (6917):860-7.

69. Ostrand-Rosenberg S, Sinha P. Myeloid-derived suppressor cells: linking inflammation and cancer. J Immunol. 2009;182(8):4499-506.

70. Reed JC, Alpers JD, Nowell PC, Hoover RG. Sequential expression of protooncogenes during lectin-stimulated mitogenesis of normal human lymphocytes. Proc Natl Acad Sci U S A. 1986;83(11):3982-6.

71. Terada N, Lucas JJ, Gelfand EW. Differential regulation of the tumor suppressor molecules, retinoblastoma susceptibility gene product (Rb) and p53, during cell cycle progression of normal human T cells. J Immunol. 1991;147(2):698-704

72. Boehme SA, Lenardo MJ. TCR-mediated death of mature T lymphocytes occurs in the absence of p53. J Immunol. 1996;156(11):4075-8.

73. Tak PP, Zvaifler NJ, Green DR, Firestein GS. Rheumatoid arthritis and p53: how oxidative stress might alter the course of inflammatory diseases. Immunol Today. 2000;21(2):78-82.

74. Yamanishi Y, Boyle DL, Rosengren S, Green DR, Zvaifler NJ, Firestein GS. Regional analysis of p53 mutations in rheumatoid arthritis synovium. Proc Natl Acad Sci U S A. 2002;99(15):10025-30

75. Tapinos NI, Polihronis M, Moutsopoulos HM. Lymphoma development in Sjogren's syndrome: novel p53 mutations. Arthritis Rheum. 1999;42(7):1466-72.

76. Zheng SJ, Lamhamedi-Cherradi SE, Wang P, Xu L, Chen YH. Tumor suppressor p53 inhibits autoimmune inflammation and macrophage function. Diabetes. 2005:54(5):1423-8.

77. Okuda Y, Okuda M, Bernard CC. Regulatory role of p53 in experimental autoimmune encephalomyelitis. J Neuroimmunol. 2003;135(1-2):29-37.

78. He D, Li H, Yusuf N, Elmets CA, Li J, Mountz JD, et al. IL-17 promotes tumor development through the induction of tumor promoting microenvironments at tumor sites and myeloid-derived suppressor cells. J Immunol. 2010;184 (5):2281-8.

79. Wang L, Yi T, Kortylewski M, Pardoll DM, Zeng D, Yu H. IL-17 can promote tumor growth through an IL-6-Stat3 signaling pathway. J Exp Med. 2009;206(7):1457-64

80. Wang L, Yi T, Zhang W, Pardoll DM, Yu H. IL-17 enhances tumor development in carcinogen-induced skin cancer. Cancer Res. 2010;70(24):10112-20.

81. Addadi Y, Moskovits N, Granot D, Lozano G, Carmi Y, Apte RN, et al. p53 status in stromal fibroblasts modulates tumor growth in an SDF1dependent manner. Cancer Res. 2010;70(23):9650-8.

82. Moskovits N, Kalinkovich A, Bar J, Lapidot T, Oren M. p53 Attenuates cancer cell migration and invasion through repression of SDF-1/CXCL12 expression in stromal fibroblasts. Cancer Res. 2006;66(22):10671-6.

83. Riley T, Sontag E, Chen P, Levine A. Transcriptional control of human p53-regulated genes. Nat Rev. 2008;9(5):402-12.

84. Donehower LA, Lozano G. 20 years studying p53 functions in genetically engineered mice. Nat Rev Cancer. 2009;9(11):831-41.

85. Levine AJ. The common mechanisms of transformation by the small DNA tumor viruses: The inactivation of tumor suppressor gene products: $\mathrm{p53}$. Virology. 2009;384(2):285-93.

86. Havre PA, Yuan J, Hedrick L, Cho KR, Glazer PM. p53 inactivation by HPV16 E6 results in increased mutagenesis in human cells. Cancer Res. 1995;55 (19):4420-4.

87. Jiang D, Srinivasan A, Lozano G, Robbins PD. SV40 T antigen abrogates p53-mediated transcriptional activity. Oncogene. 1993;8(10):2805-12.

88. Feng Z, Hu W, Teresky AK, Hernando E, Cordon-Cardo C, Levine AJ. Declining p53 function in the aging process: a possible mechanism for the increased tumor incidence in older populations. Proc Natl Acad Sci U S A. 2007;104 (42):16633-8 
89. Ak P, Levine AJ. p53 and NF-kappaB: different strategies for responding to stress lead to a functional antagonism. Faseb J. 2010;24(10):3643-52.

90. Kawauchi K, Araki K, Tobiume K, Tanaka N. Activated p53 induces NF-kappaB DNA binding but suppresses its transcriptional activation. Biochem Biophys Res Commun. 2008;372(1):137-41.

91. Son DS, Kabir SM, Dong YL, Lee E, Adunyah SE. Inhibitory effect of tumor suppressor p53 on proinflammatory chemokine expression in ovarian cancer cells by reducing proteasomal degradation of IkappaB. PLoS One. 2012;7(12):e51116.

92. Schwitalla S, Ziegler PK, Horst D, Becker V, Kerle I, Begus-Nahrmann Y, et al, Loss of p53 in enterocytes generates an inflammatory microenvironment enabling invasion and lymph node metastasis of carcinogen-induced colorectal tumors. Cancer Cell. 2013;23(1):93-106.

93. Lowe JM, Menendez D, Bushel PR, Shatz M, Kirk EL, Troester MA, et al. p53 and NF-kappaB coregulate proinflammatory gene responses in human macrophages. Cancer Res. 2014;74(8):2182-92.

94. Rodier F, Campisi J. Four faces of cellular senescence. J Cell Biol. 2011;192 (4):547-56.

95. Davalos AR, Kawahara M, Malhotra GK, Schaum N, Huang J, Ved U, et al. p53-dependent release of Alarmin HMGB1 is a central mediator of senescent phenotypes. J Cell Biol. 2013;201(4):613-29.

96. Kroemer G, Galluzzi L, Kepp O, Zitvogel L. Immunogenic cell death in cancer therapy. Annu Rev Immunol. 2013:31:51-72.

97. Zitvogel L, Apetoh L, Ghiringhelli F, Andre F, Tesniere A, Kroemer G. The anticancer immune response: indispensable for therapeutic success? J Clin Invest. 2008;118(6):1991-2001.

98. Zitvogel L, Apetoh L, Ghiringhelli F, Kroemer G. Immunological aspects of cancer chemotherapy. Nat Rev Immunol. 2008;8(1):59-73.

99. Zitvogel L, Galluzzi L, Smyth MJ, Kroemer G. Mechanism of action of conventional and targeted anticancer therapies: reinstating immunosurveillance. Immunity. 2013;39(1):74-88.

100. Ma Y, Adjemian S, Mattarollo SR, Yamazaki T, Aymeric L, Yang H, et al. Anticancer chemotherapy-induced intratumoral recruitment and differentiation of antigen-presenting cells. Immunity. 2013;38(4):729-41.

101. Gasser S, Orsulic S, Brown EJ, Raulet DH. The DNA damage pathway regulates innate immune system ligands of the NKG2D receptor. Nature. 2005;436(7054):1186-90.

102. Gasser S, Raulet DH. The DNA damage response arouses the immune system. Cancer Res. 2006;66(8):3959-62.

103. Tang ML, Khan MK, Croxford JL, Tan KW, Angeli V, Gasser S. The DNA damage response induces antigen presenting cell-like functions in fibroblasts. Eur J Immunol. 2014:44(4):1108-18.

104. Li H, Lakshmikanth T, Garofalo C, Enge M, Spinnler C, Anichini A, et al. Pharmacological activation of p53 triggers anticancer innate immune response through induction of ULBP2. Cell cycle (Georgetown, Tex. 2011;10 (19):3346-58.

105. Textor S, Fiegler N, Arnold A, Porgador A, Hofmann TG, Cerwenka A. Human NK cells are alerted to induction of p53 in cancer cells by upregulation of the NKG2D ligands ULBP1 and ULBP2. Cancer Res. 2011;71(18):5998-6009.

106. Iannello A, Thompson TW, Ardolino M, Lowe SW, Raulet DH. p53-dependent chemokine production by senescent tumor cells supports NKG2D-dependent tumor elimination by natural killer cells. J Exp Med. 2013;210(10):2057-69

107. Meng Y, Efimova EV, Hamzeh KW, Darga TE, Mauceri HJ, Fu YX, et al. Radiation-inducible immunotherapy for cancer: senescent tumor cells as a cancer vaccine. Mol Ther. 2012;20(5):1046-55.

108. Zhang B, Bowerman NA, Salama JK, Schmidt H, Spiotto MT, Schietinger A, et al. Induced sensitization of tumor stroma leads to eradication of established cancer by T cells. J Exp Med. 2007:204(1):49-55.

109. Burnette BC, Liang H, Lee $Y$, Chlewicki L, Khodarev NN, Weichselbaum RR, et al. The efficacy of radiotherapy relies upon induction of type interferon-dependent innate and adaptive immunity. Cancer Res. 2011;71 (7):2488-96

110. Formenti SC, Demaria S. Systemic effects of local radiotherapy. Lancet Oncol. 2009;10(7):718-26.

111. Formenti SC, Demaria S. Combining radiotherapy and cancer immunotherapy: a paradigm shift. J Natl Cancer Inst. 2013;105(4):256-65.

112. Shatz M, Menendez D, Resnick MA. The human TLR innate immune gene family is differentially influenced by DNA stress and p53 status in cancer cells. Cancer Res. 2012;72(16):3948-57.
113. Taura M, Eguma A, Suico MA, Shuto T, Koga T, Komatsu K, et al. p53 regulates Toll-like receptor 3 expression and function in human epithelial cell lines. Mol Cell Biol. 2008;28(21):6557-67.

114. Mori T, Anazawa Y, liizumi M, Fukuda S, Nakamura Y, Arakawa H. Identification of the interferon regulatory factor 5 gene (IRF-5) as a direct target for p53. Oncogene. 2002;21(18):2914-8.

115. Dharel N, Kato N, Muroyama R, Taniguchi H, Otsuka M, Wang Y, et al. Potential contribution of tumor suppressor p53 in the host defense against hepatitis C virus. Hepatology. 2008;47(4):1136-49.

116. Shen Y, Wang X, Guo L, Qiu Y, Li X, Yu H, et al. Influenza A virus induces p53 accumulation in a biphasic pattern. Biochem Biophys Res Commun. 2009;382(2):331-5

117. Moiseeva O, Mallette FA, Mukhopadhyay UK, Moores A, Ferbeyre G. DNA damage signaling and p53-dependent senescence after prolonged beta-interferon stimulation. Mol Biol Cell. 2006;17(4):1583-92.

118. Munoz-Fontela C, Pazos M, Delgado I, Murk W, Mungamuri SK, Lee SW, et al. p53 serves as a host antiviral factor that enhances innate and adaptive immune responses to influenza A virus. J Immunol. 2011;187(12):6428-36.

119. Xu Y. DNA damage: a trigger of innate immunity but a requirement for adaptive immune homeostasis. Nat Rev Immunol. 2006;6(4):261-70.

120. Bruchard M, Mignot G, Derangere V, Chalmin F, Chevriaux A, Vegran F, et al. Chemotherapy-triggered cathepsin B release in myeloid-derived suppressor cells activates the Nlrp3 inflammasome and promotes tumor growth. Nat Med. 2013;19(1):57-64.

121. Cheok CF, Verma CS, Baselga J, Lane DP. Translating p53 into the clinic. Nat Rev Clin Oncol. 2011:8(1):25-37.

122. Muller PA, Vousden KH. Mutant p53 in cancer: new functions and therapeutic opportunities. Cancer Cell. 2014;25(3):304-17.

123. Khoo KH, Verma CS, Lane DP. Drugging the p53 pathway: understanding the route to clinical efficacy. Nat Rev Drug Discov. 2014;13(3):217-36.

124. Gomez-Manzano C, Fueyo J, Kyritsis AP, Steck PA, Roth JA, McDonnell TJ, et al. Adenovirus-mediated transfer of the p53 gene produces rapid and generalized death of human glioma cells via apoptosis. Cancer Res. 1996;56 (4):694-9.

125. Nemunaitis J, Clayman G, Agarwala SS, Hrushesky W, Wells JR, Moore C, et al. Biomarkers Predict p53 Gene Therapy Efficacy in Recurrent Squamous Cell Carcinoma of the Head and Neck. Clin Cancer Res. 2009;15(24):7719-25.

126. Lang FF, Yung WK, Sawaya R, Tofilon PJ. Adenovirus-mediated p53 gene therapy for human gliomas. Neurosurgery. 1999;45(5):1093-104.

127. Bischoff JR, Kirn DH, Williams A, Heise C, Horn S, Muna M, et al. An adenovirus mutant that replicates selectively in p53-deficient human tumor cells. Science. 1996;274(5286):373-6

128. Heise C, Ganly I, Kim YT, Sampson-Johannes A, Brown R, Kirn D. Efficacy of a replication-selective adenovirus against ovarian carcinomatosis is dependent on tumor burden, viral replication and p53 status. Gene Ther. 2000;7 (22):1925-9.

129. Nemunaitis J, Ganly I, Khuri F, Arseneau J, Kuhn J, McCarty T, et al. Selective replication and oncolysis in p53 mutant tumors with ONYX-015, an E1B-55kD gene-deleted adenovirus, in patients with advanced head and neck cancer: a phase II trial. Cancer Res. 2000;60(22):6359-66.

130. Nemunaitis J, Swisher SG, Timmons T, Connors D, Mack M, Doerksen L, et al. Adenovirus-mediated p53 gene transfer in sequence with cisplatin to tumors of patients with non-small-cell lung cancer. J Clin Oncol. 2000;18(3):609-22.

131. Chiocca EA, Abbed KM, Tatter S, Louis DN, Hochberg FH, Barker F, et al. A phase I open-label, dose-escalation, multi-institutional trial of injection with an E1B-Attenuated adenovirus, ONYX-015, into the peritumoral region of recurrent malignant gliomas, in the adjuvant setting. Mol Ther. 2004;10(5):958-66.

132. Pflaum J, Schlosser S, Muller M. p53 Family and Cellular Stress Responses in Cancer. Front Oncol. 2014;4:285

133. Vassilev LT, Vu BT, Graves B, Carvajal D, Podlaski F, Filipovic Z, et al. In vivo activation of the 553 pathway by small-molecule antagonists of MDM2. Science. 2004:303(5659):844-8

134. Saha MN, Micallef J, Qiu L, Chang H. Pharmacological activation of the p53 pathway in haematological malignancies. J Clin Pathol. 2010;63 (3):204-9.

135. Issaeva N, Bozko P, Enge M, Protopopova M, Verhoef LG, Masucci M, et al. Small molecule RITA binds to p53, blocks p53-HDM-2 interaction and activates p53 function in tumors. Nat Med. 2004:10(12):1321-8.

136. Gasparini C, Tommasini A, Zauli G. The MDM2 inhibitor Nutlin-3 modulates dendritic cell-induced T cell proliferation. Hum Immunol. 2012;73(4):342-5 
137. Secchiero P, Toffoli B, Melloni E, Agnoletto C, Monasta L, Zauli G. The MDM2 inhibitor Nutlin-3 attenuates streptozotocin-induced diabetes mellitus and increases serum level of IL-12p40. Acta Diabetol. 2013;50 (6):899-906.

138. Bykov VJ, Issaeva N, Shilov A, Hultcrantz M, Pugacheva E, Chumakov P, et al. Restoration of the tumor suppressor function to mutant p53 by a low-molecular-weight compound. Nat Med. 2002;8(3):282-8.

139. Stegh AH. Targeting the p53 signaling pathway in cancer therapy - the promises, challenges and perils. Expert Opin Ther Targets. 2012;16(1):67-83.

140. Melero I, Arina A, Murillo O, Dubrot J, Alfaro C, Perez-Gracia JL, et al. Immunogenic cell death and cross-priming are reaching the clinical immunotherapy arena. Clin Cancer Res. 2006;12(8):2385-9.

\section{Submit your next manuscript to BioMed Central and take full advantage of:}

- Convenient online submission

- Thorough peer review

- No space constraints or color figure charges

- Immediate publication on acceptance

- Inclusion in PubMed, CAS, Scopus and Google Scholar

- Research which is freely available for redistribution 